\title{
Criticality Index of Building Systems Using Multi-Criteria Decision Analysis Technique
}

\author{
Dabo Baba Hammad ${ }^{1}$, Nasir Shafiq ${ }^{2}$, Muhd Fadhil Nuruddin ${ }^{3}$ \\ 1,2,3 Department of Civil Engineering, Universiti Teknologi PETRONAS, Bandar Seri Iskandar, 31750 \\ Tronoh Perak, Malaysia
}

\begin{abstract}
One of the most significant step in building structure maintenance decision is the physical inspection of the facility to be maintained. The physical inspection involved cursory assessment of the structure and ratings of the identified defects based on expert evaluation. The objective of this paper is to describe present a novel approach to prioritizing the criticality of physical defects in a residential building system using multi criteria decision analysis approach. A residential building constructed in 1985 was considered in this study. Four criteria which includes; Physical Condition of the building system (PC), Effect on Asset (EA), effect on Occupants (EO) and Maintenance Cost (MC) are considered in the inspection. The building was divided in to nine systems regarded as alternatives. Expert's choice software was used in comparing the importance of the criteria against the main objective, whereas structured Proforma was used in quantifying the defects observed on all building systems against each criteria. The defects severity score of each building system was identified and later multiplied by the weight of the criteria and final hierarchy was derived. The final ranking indicates that, electrical system was considered the most critical system with a risk value of 0.134 while ceiling system scored the lowest risk value of 0.066 . The technique is often used in prioritizing mechanical equipment for maintenance planning. However, result of this study indicates that the technique could be used in prioritizing building systems for maintenance planning
\end{abstract}

\section{Introduction}

Over some years, maintenance strategies have progressed tremendously from the traditional breakdown maintenance to more sophisticated strategy like condition monitoring and reliability centered maintenance [1]. This can be attributed to the changes in maintenance approaches due to growing needs of serviceability of facilities and structures which imposes new challenging requirement to the facility management [2]. The reasons for sudden changes in the field of maintenance management are (i) complexity of maintenance system due to rapid technological changes (ii) impact hidden cost of maintenance on competitiveness and survivability in service (iii) apparent need for maintenance and facility management in enhancing safety and eco-efficient paradigms [3]. Moreover, in case of building structures, aggressive environment possess serious risk to the structural performance of the building [4]. Similarly, cracking failure in walls is detectable and can be physically evaluated and quantified [5]

Building structural system, being complex with extended characteristic of structural material and structural system hierarchy requires holistic approach to inspection and evaluation [6,7]. On this note, 
maintenance for safety and serviceability of a building during its lifecycle is indispensable. According to Frangopol and Liu [8] most existing maintenance and management systems are developed on the basis of life-cycle cost minimization only. While forecasting and calculation of reliability and durability remain a challenge [9], single maintenance and management solution obtained through this method does not result to acceptable long-term structure performance, the structure performance is usually described by the visual inspection-based on structure condition only. Building deterioration does not only occur in physical term [10] but also in; Economic-depreciation or reduction in capital or rental value of the property. Legal-increase noncompliance with statutory requirement. Environmental-increase pollution and blight leading to an unsustainable building. Functional-partial or full cessation of use leading to redundancy of the deteriorated building and finally, Social-reduction in or loss of amenity owing to obsolescence or redundancy. Like industrial machineries, the life cycle cost of a building covers all the performance indices of such building [11] including even microclimate conditions within the building environment [12]. The structure social levels such as safety, reputation, and environment are not adequately considered in determining maintenance management decision.

Therefore, in any meaningful maintenance planning, there is a need to use all possible criteria in assessing all possible sources of defect and their general implications on the building. In support of this claim, Petrovsky and Lovanov [13] opines that, comparison of different clusters and selection of the most preferable option is an ill-structured and complex problem which often involved both subjective and objective attributes. On this note, this study considered multiple criteria in evaluating the multiple alternatives of a building system. Therefore one of the useful tools that can be used in prioritizing the criticality of the various building system using multiple criteria is Analytic Hierarchy Process (AHP). The tool was developed in Wharton School of Business by Saaty [14]. According to Arif et. al. [15], the tool has been widely used to solve multi-criteria decision making in both academic research and industrial practice. Similarly, the tool has been extensively applied in risk analysis as opined by Marques [16]. Hence, the objective of this paper is to describe the concept of risk based maintenance and illustrates the use of semi-quantitative risk analysis method in prioritizing the criticality of physical defects in residential building system.

\section{Methodology}

The study uses two methodologies, which is analytic Hierarchy process (AHP) and condition survey of the building system. The AHP was used in weighting the importance of each criterion against the main objective to identify the most critical defect in building system. AHP is a widely used multi-criteria decision making tool [17]. Developed by Saaty [18], AHP provides a proven, effective means to deal with complex decision making and can assist in identifying and weighing criteria, analyzing the data collected and enhances the decision making process. When making a complex decision, first, the decision problem is decomposed in to hierarchy with the top level representing the goal of the decision and the middle level representing the criteria and the lowest level representing the alternatives. In the context of this paper, the hierarchy composed of main object that is prioritizing the criticality of defects in building systems and the criteria used are; PC: Physical condition, EA: Effect on Assets, EO: Effect on Occupants and MC: Maintenance cost. While building systems considered as the alternatives are; FS $=$ Floor System, WS $=$ Wall System, DW = Doors $/$ Windows, CS $=$ Ceiling System, $\mathrm{RT}=$ Roof Trusses, $\mathrm{RS}=$ Roofing Sheets, ES=Electrical system, DS= Drainage system, $\mathrm{WF}=$ Wall finishing. These systems are chosen for this study because they form the most critical sets of conventional building envelope. According to [18], the main principles of AHP are three. They are; Hierarchy framework, Priority Analysis and consistency verification. However, due to the fact that, the work is on progress, the scope of this paper does not cover the final stage that is consistency verification. Thus, it is limited to the second stage that is, priority analysis only. After constructing the hierarchy, as shown on figure 2, Analytic Hierarchy Process ratio scale (Table 1) is used in comparing the importance of criteria against the main goal. On the other hand, the condition survey is used in 
evaluating and ranking of the physical observable defects in the building systems using a defined Proforma as shown is appendix 1. A condition survey is aimed at carrying out a close and more intensive examination of all elements of the structures [19]. The condition survey may be required for routine maintenance, rehabilitation, modification, of the service condition, investigation of the structural stability, and study of the performance of material under a specific exposure condition [20]. Therefore, in formulating any maintenance planning or activity, the condition survey has to be carried out first. The condition survey often seeks to identify three condition matrixes which includes; importance of defects, intensity of defects and extends of defects. Hence, in the context of this work, the experts surveyed the defects based on the physical condition of the defects (intensity of the defect), effect of the defect on the facility (extent of the defect), effect on occupants of the building and the probable maintenance cost of the defects. Each defect is ranked against the four criteria on a scale of (1-9). The scale of 1- 9 was chosen to comply with the AHP ratio scale.

Table 1 : AHP scale [18]

\begin{tabular}{|l|l|}
\hline Judgment & Score \\
\hline Equal & 1 \\
\hline Weak & 3 \\
\hline Strong & 5 \\
\hline Very strong & 7 \\
\hline Absolute & 9 \\
\hline
\end{tabular}

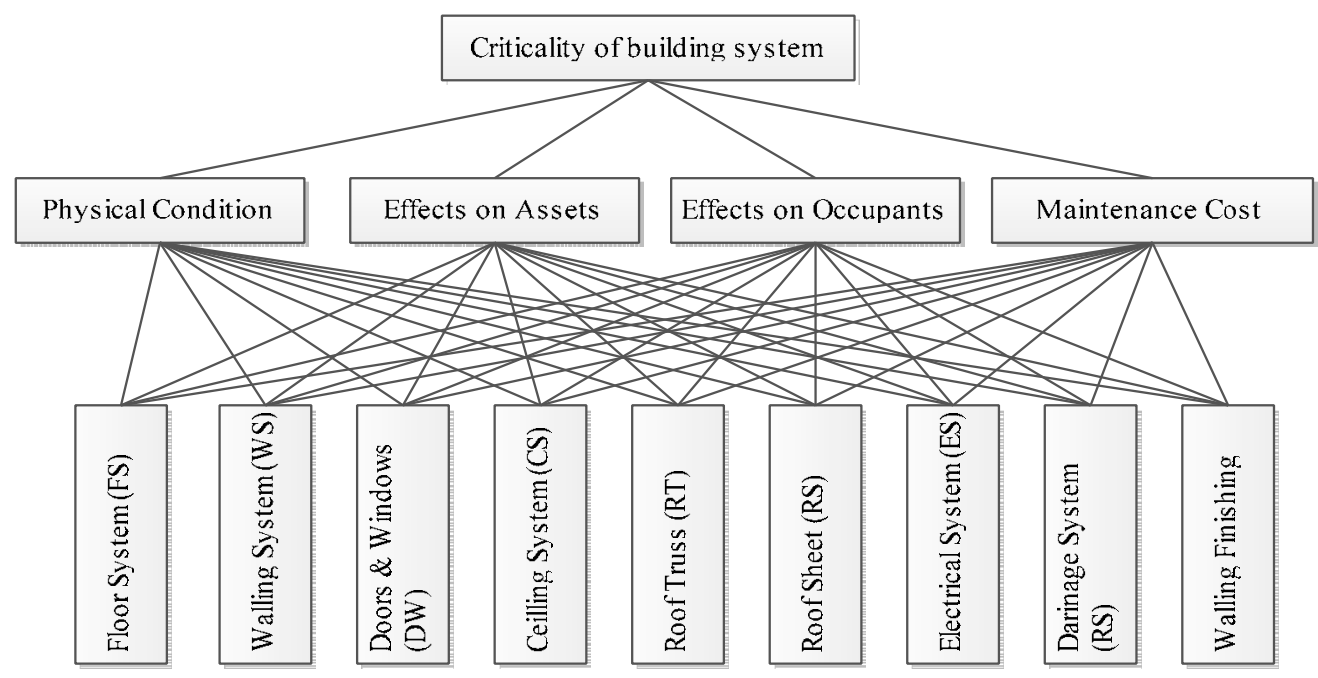

Figure 1: Hierarchy model for ranking defects in building systems

Table 2: Physical Condition (PC) scale of the building system

\begin{tabular}{|c|c|c|c|}
\hline No & $\begin{array}{l}\text { Model } \\
\text { Scale }\end{array}$ & Chronology value & Physical Condition \\
\hline \multirow{5}{*}{1} & 1 & epair is not needed & fects \\
\hline & 3 & $\begin{array}{l}\text { Repair is needed within the period } \\
\text { of } 1-2 \text { years }\end{array}$ & $\begin{array}{l}\text { Structural element is structurally functional but need } \\
\text { minor repair }\end{array}$ \\
\hline & 5 & $\begin{array}{l}\text { Repair is needed within the period } \\
\text { of } 6-12 \text { months }\end{array}$ & $\begin{array}{l}\text { Structural element is functionally sound but require } \\
\text { urgent repair }\end{array}$ \\
\hline & 7 & $\begin{array}{l}\text { Repair is needed within the period } \\
\text { of } 1-6 \text { moths }\end{array}$ & $\begin{array}{l}\text { Serious defect, structural element can function but not } \\
\text { to an acceptable standard }\end{array}$ \\
\hline & 9 & Repair is required immediately & Structural member is not functioning at all. \\
\hline
\end{tabular}


Table 2 is a rating of physical condition of a defect. In order to rank this parameter sometime, measurement of size in case of cracks using crack gauge or measuring rule and measurement of hardness using rebound hammer or ultrasonic pulse velocity (UPV) may be required.

Table 3: Effect on Asset (EA) Criteria Scale

\begin{tabular}{llll}
\hline No & $\begin{array}{l}\text { Scale } \\
\text { value }\end{array}$ & Chronology value & Linguistic value \\
\hline \multirow{2}{*}{$\mathbf{2}$} & 1 & Has no effect on other structure/component & No damage \\
& 3 & May have a slight effect on the other structure & Minor damage \\
& 5 & Some damage to only an individual structure & Local damage \\
& 7 & Damage to a structure that may affect co-joint structure & Major damage \\
& 9 & Major damage that may lead to total failure of a system of & Excessive damage \\
\hline
\end{tabular}

The criterion in Table 3 is concerned with the possible impact the defect may have on an adjoined component (s) or system. Reference may be made to design in order to ascertain the relationship between the system or components/structure that has already developed a defect and its adjoining member.

Table 4 : Effect on Occupant (EO) Criteria scale

\begin{tabular}{|c|c|c|c|}
\hline No & $\begin{array}{l}\text { Scale } \\
\text { value }\end{array}$ & Chronology value & Linguistic value \\
\hline \multirow{5}{*}{3} & 1 & $\begin{array}{l}\text { No impact to human, environment } \\
\text { or operation facilities }\end{array}$ & No impact \\
\hline & 3 & Has negligible effect on occupants & Minor Impact \\
\hline & 5 & Has Moderate impact on occupants & Localized impact \\
\hline & 7 & Impact on occupant or human is imminent. & High Impact \\
\hline & 9 & Has catastrophic impact - may lead to loss of live & Catastrophic impact \\
\hline
\end{tabular}

Table 4 is concerned with the safety and environmental impact the defect may have on the occupants of the building. Scoring of this criterion may also require an in-depth understanding of the functionality and material characteristics of the system/component. Drainage pipe from WC may have a higher impact on the occupants than crack on the floor.

Table 5 : Maintenance Cost (MC) Criteria scale

\begin{tabular}{llll}
\hline No & $\begin{array}{l}\text { Scale } \\
\text { value }\end{array}$ & Chronology value & Linguistic value \\
\hline 4 & 1 & $\begin{array}{l}\text { Defect cost no significant cost to maintenance of the } \\
\text { building system }\end{array}$ & Very Low \\
& 3 & $\begin{array}{l}\text { Defect may cause significant cost on maintenance of the } \\
\text { system }\end{array}$ & Moderate \\
& 5 & $\begin{array}{l}\text { Defect may demand for high direct cost/repair cost } \\
\text { System may requires very high cost for partial replacement }\end{array}$ & $\begin{array}{l}\text { High } \\
\text { Very high }\end{array}$ \\
& & System may requires extremely high cost to be replaced. & Extremely high \\
\hline
\end{tabular}

Table 5 refers to the probable cost of restoring affected component to its original designed condition. Defect that may require extensive technical skills and sophisticated maintenance tool may cost higher and therefore could be ranked higher. Nominal defects such as cracks on the lower part of wall that may require neither scaffolding nor crane may be ranked low if the repair material is within the reach 


\section{Data Analysis and Results}

Since this technique is a hybrid approach, the total ranking value of all defects in the building systems will be summed to derive the total score of the defects against each criterion. Then each individual score is divided by the total sum of the score. For instance in Table 6, to obtained normalized value of $\mathrm{FS}$ against $\mathrm{PC}=6 / 56=0.107$.

Table 6: Alternative evaluation of each criterion

\begin{tabular}{|c|c|c|c|c|c|c|c|c|}
\hline & PC & $\frac{P C_{i}}{\sum_{i} P C_{i}}$ & EA & $\frac{E A_{i}}{\sum_{i} E A_{i}}$ & EO & $\begin{array}{c}E O_{i} \\
\sum_{i} E O_{i}\end{array}$ & MC & $\frac{M C_{i}}{\sum_{i} M C_{i}}$ \\
\hline FS & 6 & 0.107 & 5 & 0.102 & 5 & 0.098 & 5 & 0.094 \\
\hline WS & 6 & 0.107 & 5 & 0.102 & 4 & 0.078 & 7 & 0.132 \\
\hline DW & 5 & 0.089 & 4 & 0.082 & 7 & 0.137 & 9 & 0.170 \\
\hline $\mathrm{CS}$ & 5 & 0.089 & 3 & 0.061 & 3 & 0.059 & 4 & 0.075 \\
\hline $\mathrm{RT}$ & 5 & 0.089 & 4 & 0.082 & 5 & 0.098 & 5 & 0.094 \\
\hline RS & 6 & 0.107 & 6 & 0.122 & 6 & 0.118 & 4 & 0.075 \\
\hline ES & 7 & 0.125 & 9 & 0.184 & 9 & 0.176 & 5 & 0.094 \\
\hline DS & 7 & 0.125 & 7 & 0.143 & 7 & 0.137 & 7 & 0.132 \\
\hline WF & 9 & 0.161 & 6 & 0.122 & 5 & 0.098 & 7 & 0.132 \\
\hline Total & 56 & & 49 & & 51 & & 53 & \\
\hline
\end{tabular}

Then, the priority values of the criteria as shown in Table 7 were obtained by pair wise comparison using expert choice software

Table 7: Priority values of criteria obtained using AHP

\begin{tabular}{cc}
\hline Criteria & Priority (wi) \\
\hline PC & .296 \\
MC & .253 \\
EO & .199 \\
EA & .169 \\
\hline
\end{tabular}

Table 8 shows the overall priority vector of the alternatives with respect to the criteria. The overall priority vector was obtained by multiplying the priority vector for the building system (alternatives) and the priority vector of the criteria obtained from expert choice software and presented in Table 7. The result of the multiplication of alternative under each criterion will then be added together to obtained the final ranking. An example of the overall priority for Floor System (FS) is $0.032+0.026+0.020+0.0159=0.093$.

Table 8 Overall Priority vector for the alternatives with respect to the criteria

\begin{tabular}{|c|c|c|c|c|c|c|c|c|c|}
\hline & PC & $\sum_{i} \stackrel{P C_{i}}{P C_{i}} \times w^{i}$ & EA & $\frac{E A_{i}}{\sum_{i} E A_{i} \mathrm{x}} w^{i}$ & EO & $\underset{\sum_{i} \frac{E O_{i}}{E O_{i}} \times w^{i}}{i}$ & $\mathrm{MC}$ & $\frac{M C_{i}}{\sum_{i} M C_{i} \times} w^{i}$ & $\begin{array}{c}\text { Final } \\
\text { Hierarchy }\end{array}$ \\
\hline & & 1 & & 2 & & 3 & & 4 & $\Sigma(1,2,3,4)$ \\
\hline FS & 0.107 & 0.032 & 0.102 & 0.026 & 0.098 & 0.020 & 0.094 & 0.0159 & 0.093 \\
\hline WS & 0.107 & 0.032 & 0.102 & 0.026 & 0.078 & 0.016 & 0.132 & 0.0223 & 0.095 \\
\hline DW & 0.089 & 0.026 & 0.082 & 0.021 & 0.137 & 0.027 & 0.170 & 0.0287 & 0.103 \\
\hline $\mathrm{CS}$ & 0.089 & 0.026 & 0.061 & 0.015 & 0.059 & 0.012 & 0.075 & 0.0127 & 0.066 \\
\hline RT & 0.089 & 0.026 & 0.082 & 0.021 & 0.098 & 0.020 & 0.094 & 0.0159 & 0.082 \\
\hline RS & 0.107 & 0.032 & 0.122 & 0.031 & 0.118 & 0.023 & 0.075 & 0.0127 & 0.099 \\
\hline ES & 0.125 & 0.037 & 0.184 & 0.047 & 0.176 & 0.035 & 0.094 & 0.0159 & 0.134 \\
\hline DS & 0.125 & 0.037 & 0.143 & 0.036 & 0.137 & 0.027 & 0.132 & 0.0223 & 0.123 \\
\hline WF & 0.161 & 0.048 & 0.122 & 0.031 & 0.098 & 0.020 & 0.132 & 0.0223 & 0.120 \\
\hline
\end{tabular}




\section{Conclusion}

Pair wise comparison of criteria for criticality ranking of defects in building was obtained using experts' choice software. Subjective judgment of building defects was obtained using physical survey. Therefore, criticality ranking of defects in building systems has been estimated using analytic hierarchy process as a multiple criteria decision analysis tool. Based on the analysis of the data generated for this study, defect in electrical system (ES) has been ranked the highest with 0.134 . This is indicating that electrical system is the most severe and critical system from among the building systems. Therefore maintenance of electrical system requires prompt attention probably due to its volatility and importance. However, Ceiling System (CS) rated the lowest in this study. Ceiling system may have less structural effects on the occupants. Practically, a defect in ceiling may not render a room inhabitable and there are many optional alternatives that can replace the function of the ceiling system. Hence, this technique could be used in ranking any type of defects in engineering system where design data cannot be obtained. However, this study could be extended by considering more criteria and sub-criteria as well as more alternatives and sub-alternatives may be added to this model.

\section{References}

1. F. I. Khan, R. Sadiq and M. M. Haddara, "Risk-Based Inspection and Maintenance (RBIM): Multi-Attribute Decision-Making with Aggregative Risk Analysis," Process Saf. Environ. Prot., vol. 82, pp. 398-411, 11, 2004.

2. R. Cigolini, L. Fedele, M. Garetti and M. Macchi, "Recent advances in maintenance and facility management," Production Planning \& Control, vol. 19, pp. 279-286, 06/01; 2012/09, 2008.

3. P. S. Gahlot and S. '. Sharma, Building Repair and Maintenance Management. India: CBS Publisher, 2006.

4. V. Belov and A. Veselov, "Mechanics of Corroded Flexible Reinforced-Concrete Elements," World Applied Science Journal (WASJ), vol. 23, pp. 197-202, 2013.

5. M. Behrooyan, H. Razaghi and S. A. Alavi, "Strenght and Ductility in Retrofitted URM Walls by GFRP and CFRP," World Applied Science Journal (WASJ), vol. 18, pp. 554-558, 2012.

6. S. I. Merkulov, R. V. Lesovic, A. A. Metrohin and N. V. Kalashnikov, "Development of Theory of Safety for Structural Building and Construction," World Applied Science Journal (WASJ), vol. 31, pp. 531-533, 2014.

7. J. A. Zargaryun and V. I. Finaev, "Multicriteria Decision Making in Case of Incomplete Source of Date," World Applied Science Journal (WASJ), vol. 23, pp. 1253-1261, 2013.

8. D. M. Frangopol and M. Liu, "Maintenance and management of civil infrastructure based on condition, safety, optimization, and life-cycle cost*," Structure and Infrastructure Engineering, vol. 3, pp. 29-41, 03/01; 2012/09, 2007.

9. Y. A. Izvekov, V. V. Dubrobsky and E. Y. Hamutskikh, "Mathematical Modeling and Calculation of Accuracy and Durability of Mecahnical Systems' Elements," World Applied Science Journal, vol. 30, pp. 32-34, 2014

10. J. Douglas and B. Ransom, Understanding Building Failure. Taylor and Francis London, 2001.

11. S. M. Niari, I. Ranjbar and M. Rashidi, "Predicting of Repair and Maintenance Cost of John Deere 4955 Tractors in Ardabil Province, Iran," World Applied Science Journal, vol. 19, pp. 1412-1416, 2012.

12. T. Ducjuk and A. Grimitlin, "Aeration of Industrial Buildings," World Applied Science Journal (WASJ), vol. 23, pp. 50-54, 2013.

13. A. B. Petrovsky and V. N. Lovanov, "Selection of Complex System in the Reduced Multiple Criteria Space," World Applied Science Journal (WASJ), vol. 29, pp. 1315-1319, 2014.

14. T. Saaty L., Decision Making with Analytic Network Process: Economic, Political, Social and Technological Applications with Benefits, Opportunities, Costs and Risks. USA: Springer Science Business Media, LLC, 2006. 
15. H. Arif, M. S. Salit, N. Ismail and Y. Nukman, "Use of Analytic Hierarchy Process (AHP) For Selecting the best Design Concept," Jurnal Teknologi, vol. 49, pp. 1-18, 2008.

16. A. C. Márquez, "Maintenance Management Characterization: Process, Framework and Supporting Pillars," pp. 11-40, 2007.

17. D. Dalalah, F. Al-Oqba and M. Hayajmeh, "Application of the Analystic Hierarchy Process (AHP) in Mult-Criteria Analysis of the Selection of Cranes," JJME, Jordan Journal of Mechanical and Industrial Engineering, vol. 4, pp. 567-578, 2010.

18. T. Saaty L., Fundametal of Decision Making and Priority Setting Theory with the Analytic Hierarchy Process. RWS Publication, 2006.

19. Z. Li, C. Leung and Y. Xi, Structural Renovation in Concrete. USA and Canada: Spoons Press, 2009.

20. A. Straub, "Dutch standard for condition assessment of buildings," Structural Survey, vol. 27, pp. 23-35, 2009. 